\title{
Hemodialysis Principles and Controversies
}

\author{
Parin Makadia, Payam Benson, Filberto Kelly and Joshua Kaplan \\ New Jersey Medical School, \\ United States of America
}

\section{Introduction}

The incidence rates of End-stage renal disease (ESRD) have increased steadily internationally since 1989. The United States has the highest incident rate of ESRD, followed by Japan; Japan has the highest prevalence per million population, with the United States second (1). Of the 490,000 patients with ESRD in the United States, more than 380,000 are currently on hemodialysis (HD) (2).

ESRD on HD disproportionately affects minority populations. Whites represent the majority of the HD population (59.8\%), while African Americans (33.2\%), Asians (3.6\%), and Native Americans $(1.6 \%)$ comprise the rest of the ESRD population. However, the incidence rate of ESRD among African Americans is 4-fold higher and Native Americans 2-fold higher than that for whites. ESRD is slightly more prevalent in men than in women (male-to-female ratio, 1.2:1) and more prevalent in older adults (3).

\section{Morbidity/mortality}

Chronic renal failure is associated with a very high morbidity and hospitalization rate, likely due to existing comorbid conditions, such as hypertension, coronary artery disease, and peripheral vascular disease. The first-year age-adjusted mortality rate of patients on dialysis is $9.4 \%$, the two-year mortality rate is $32.3 \%$, and the 5 -year mortality rate is $60.8 \%$ (3). ESRD patients with diabetes have a first-year mortality rate of $23 \%$ (3). In patients with ESRD, cardiovascular disease is the primary cause of death, followed by sepsis and cerebrovascular disease. The dialysis population in the United States has a 10- to 20 -fold higher risk of death due to cardiovascular complications than the general population after adjusting for age, race, and sex. The relative risk with respect to the general population is much higher in younger patients, with cardiovascular event rates in ESRD patients in their 20s equivalent to the event rates in the general population in their 80s (3). Increased understanding of the disease process, new insights into pathogenic mechanisms, and new therapeutic options are emerging that may improve survival rates and quality of life for patients with ESRD.

\section{The need for dialysis}

Given the poor outcomes for patients on HD, every effort should be undertaken to preserve residual renal function, which is associated with improved survival (4). Early nephrology referrals, patient education, and consideration of transplant options may be helpful in decreasing the progression to ESRD. Preparation for dialysis therapy is critical for the 
smooth transition from CKD care to ESRD. Poor planning for initiation of dialysis is a major cause of increased morbidity and mortality. The use of temporary or tunneled dialysis catheters contributes to dialysis mortality by increasing the incidence of sepsis, acting as a stimulus for chronic inflammation, and damaging the central veins, thereby preventing or shortening the survival of more permanent vascular access once created. The chapter will discuss in detail regarding type of dialysis access.

\subsection{Indications for initiation of dialysis}

The appropriate time to initiate dialysis for a patient is not clearly defined. The decision to initiate dialysis in a patient with CKD involves the consideration of subjective and objective parameters by the physician and the patient. Over the past decade a trend of increasing estimated glomerular filtration rate (eGFR) at the initiation of dialysis for treatment of ESRD has been noted in the United States. In 1996, only 19\% of patients began dialysis therapy with an eGFR of greater than $10 \mathrm{ml} / \mathrm{min} / 1.73 \mathrm{~m}^{2}$ (denoted as 'early start'), but by 2005 the fraction of early start dialysis patients had risen to $45 \%$ (5). It is not known whether early start of dialysis is beneficial, harmful or neutral with respect to the outcome of dialysis treatment for ESRD (5). The timing of initiation of dialysis for ESRD is a matter of clinical judgment guided by values of residual renal function and symptoms and signs present in the patients, including those related to comorbidity. By the time the eGFR falls below 10 $\mathrm{ml} / \mathrm{min} / 1.73 \mathrm{~m}^{2}$, most patients require dialysis. However, many patients appear to function quite well until the eGFR approaches $5 \mathrm{ml} / \mathrm{min} / 1.73 \mathrm{~m}^{2}$. As a general rule, patients with diabetes require earlier intervention (eGFR $<15 \mathrm{ml} / \mathrm{min} / 1.73 \mathrm{~m}^{2}$ ) than do those with other etiologies for renal failure (6). Clearly, dialysis must be initiated before the uremic symptoms of peripheral neuropathy, encephalopathy, malnutrition, or serositis (including pericarditis) become evident (See Table 1).

- Pericarditis or pleuritis (urgent indication)

- Progressive uremic encephalopathy or neuropathy, with signs such as confusion, asterixis, myoclonus, wrist or foot drop, or, in severe cases, seizures (urgent indication)

- A clinically significant bleeding diathesis attributable to uremia (urgent indication)

- Fluid overload refractory to diuretics

- Hypertension poorly responsive to antihypertensive medications

- Persistent metabolic disturbances that are refractory to medical therapy; these include hyperkalemia, metabolic acidosis, hypercalcemia, hypocalcemia, and hyperphosphatemia

- Persistent nausea and vomiting

- $\quad$ Evidence of malnutrition

Table 1. Clinical indications to initiate dialysis in patients with CKD. (7)

\section{2 'Early' versus 'Late' dialysis}

There is conflicting evidence concerning the effect of the early initiation of dialysis on survival. Some retrospective and uncontrolled prospective studies have reported no survival benefits with early dialysis while others have found that early start of dialysis may be harmful (8). After a comprehensive review of the published literature by the National 
Kidney Foundation (NKF) workgroup in 1997, they recommended that initiation of dialysis be considered when the arithmetic mean of the urea and creatinine clearances fell below approximately $10.5 \mathrm{ml} / \mathrm{min} / 1.73 \mathrm{~m}^{2}$ except in well-nourished, asymptomatic patients (9). In 1999 Obrador et al., observed that 23\% of the US ESRD population, between 1995 and 1997, started dialysis at an eGFR less than $5 \mathrm{ml} / \mathrm{min} / 1.73 \mathrm{~m}^{2}$. They opined that this 'late start' of dialysis needed further examination, including studies of the impact on outcomes and cost of ESRD treatment (10).

In 2006, the NKF work group updated the guidelines for initiation of hemodialysis and stated that 'at CKD Stage 5, when the eGFR is $<15 \mathrm{ml} / \mathrm{min} / 1.73 \mathrm{~m}^{2}$, that nephrologists should evaluate the benefits, risks and disadvantages of beginning renal replacement therapy'. They also suggested that initiation of dialysis therapy before CKD Stage 5 (an eGFR of $>15 \mathrm{ml} / \mathrm{min} / 1.73 \mathrm{~m}^{2}$ ) may be appropriate in patients who have symptoms believed to be related to both their comorbidities and their level of residual kidney function (11). Only one study has reported the outcomes of patients with CKD who initiated dialysis only after the onset of symptoms due to uremia. In this prospective cohort study of 233 consecutive patients with advanced uremia, 151 were elective starters on dialysis, while 82 initially declined dialysis. Among the initial refusers, 55 percent developed a uremic emergency, while 48 percent were eventually established on maintenance dialysis. In this study, one year mortality was significantly higher among the initial refusers than the elective starters (18 versus 7 percent). However, these results are confounded by lack of randomization and by three deaths among the initial refusers resulting from treatment withdrawal (12).

Additional published studies have not been able to demonstrate any clear-cut survival benefits for early start of dialysis. The only randomized controlled trial that examined mortality and time of dialysis initiation, the IDEAL study (13), found no difference in survival between early or late initiation of dialysis. In this study, 828 patients with progressive CKD and an estimated GFR between 10.0 and $15.0 \mathrm{~mL} / \mathrm{min} / 1.73 \mathrm{~m} 2$ (as determined by the Cockcroft-Gault equation) were randomly assigned to dialysis initiation when the estimated GFR was either 10 to $14 \mathrm{~mL} / \mathrm{min} / 1.73 \mathrm{~m} 2$ or 5 to $7 \mathrm{~mL} / \mathrm{min} / 1.73 \mathrm{~m}^{2}$. The median time to the initiation of dialysis was 1.8 and 7.4 months in the early and late start groups, respectively. At a median follow-up period of 3.6 years, the authors noted no significant difference in survival (38 and 37 percent mortality, hazard ratio of 1.05 with early initiation, $95 \%$ CI of 0.83 to 1.30 ) as well as no difference in cardiovascular events, infections, or dialysis complications between the late start group and early start group.

However, these results do not imply that the initiation of dialysis can be delayed until the GFR is between 5 to $7 \mathrm{~mL} / \mathrm{min} / 1.73 \mathrm{~m}^{2}$ in all patients. The design of the IDEAL study permitted clinicians to initiate dialysis based upon the presence of symptoms due to uremia as well as on the estimated GFR. As a result, 76 percent of patients assigned to the late start arm initiated dialysis when the GFR was much greater than 5 to $7 \mathrm{~mL} / \mathrm{min} / 1.73 \mathrm{~m}^{2}$. This resulted in a mean GFR of $9.8 \mathrm{~mL} / \mathrm{min} / 1.73 \mathrm{~m}^{2}$ at the start of dialysis for the late start group, which was only $2.2 \mathrm{~mL} / \mathrm{min} / 1.73 \mathrm{~m}^{2}$ less than the mean start GFR for the early group $\left(12.0 \mathrm{~mL} / \mathrm{min} / 1.73 \mathrm{~m}^{2}\right)$. Thus, approximately 88 percent of all enrolled patients had initiated dialysis with an estimated GFR of approximately $10 \mathrm{~mL} / \mathrm{min} / 1.73 \mathrm{~m}^{2}$ or more, either because of symptoms or enrollment in the early dialysis arm (13).

A recent study published in Canadian Medical Association Journal examined trends in initiation of hemodialysis within Canada and compared the risk of death between patients with early and late initiation of dialysis (14). Using the Canadian Organ Replacement 
Registry from 2001 to 2007, the investigators identified a cohort of 25,910 patients 18 years or older who began hemodialysis. Dialysis was defined as beginning early if the eGFR exceeded $10.5 \mathrm{~mL} /$ minute/1.73 $\mathrm{m}^{2}$. Mean eGFR at initiation of dialysis increased from 9.3 $\mathrm{mL} /$ minute/1.73 $\mathrm{m}^{2}$ in 2001 to $10.2 \mathrm{~mL} /$ minute $/ 1.73 \mathrm{~m}^{2}$ in $2007(P<.001)$. During the same period, the proportion of early dialysis initiations increased from $28 \%$ (95\% confidence interval [CI], $27 \%-30 \%)$ to $36 \%(95 \%$ CI, 34\% - 37\%). Among those starting dialysis early, mean GFR at initiation was $15.5 \mathrm{~mL} /$ minute $/ 1.73 \mathrm{~m}^{2}$ vs $7.1 \mathrm{~mL} /$ minute/1.73 $\mathrm{m}^{2}$ among those who started dialysis late. For early vs late initiation of dialysis, the unadjusted hazard ratio (HR) for death was 1.48 (95\% CI, 1.43 - 1.54). This suggests that early initation is associated with higher mortality. After adjustment for demographic factors, serum albumin, primary cause of endstage renal disease, type of vascular access, comorbid conditions, late referral, and transplant status, the hazard ratio for death decreased to 1.18 (95\% CI, 1.13 - 1.23). Difference in mortality per 1000 patient-years between starting dialysis early vs late decreased after 1 year of followup but persisted and began increasing again after 24 months of follow-up, with significant differences at 6, 12, 30, and 36 months. (14)

There may be two additional advantages to early dialysis: control of hypertension and increased dietary intake. Reversal of volume overload with dialysis often leads to a reduction in blood pressure, which is typically volume-dependent in CKD. Perhaps more important, patients on dialysis patients require at least $1 \mathrm{~g} / \mathrm{kg}$ of protein per day to replace dialysis losses and maintain nitrogen balance. Thus, early institution of dialysis can allow a more liberal diet in terms of both food and fluid.

The overall conclusion of these trials largely supports current practice that dialysis initiation should be based upon clinical factors rather than the estimated GFR alone. Patients with progressive CKD require close follow up, early nephrology referral, and adequate advance dialysis planning (including the presence of a functioning peritoneal or vascular access and referral for transplantation). Among patients with progressive CKD, clinicians must be vigilant for the presence of symptoms and/or signs of uremia and dialysis should be initiated in the patient with these symptoms.

\section{Dialysis modality selection}

Although the life expectancy of patients with end-stage renal disease has improved since the introduction of dialysis in the 1960s, it is still far below that of the general population. As an example, the mean life span at age 49 in the United States is 33 years in the general population but only approximately seven years in patients receiving maintenance dialysis (15), in whom the overall five-year survival rate is about 30 to 50 percent in nondiabetics (depending upon the co-morbid diagnoses) and 25 percent in diabetics (15). Despite improvements in technology and patient care, the mortality rate of patients on maintenance dialysis remains alarmingly high, at approximately 15 to 20 percent per year (16).

There are two principal choices for maintenance dialysis: hemodialysis (HD) and peritoneal dialysis (PD). Selecting one of these modalities is influenced by a number of considerations such as availability and convenience, comorbid conditions, socioeconomic and dialysis center factors, the patient's home situation, method of physician reimbursement, and the ability to tolerate volume shifts (17-23). Most studies suggest a better survival rate in PD than in HD patients during the first few years after starting therapy (24). However, after 2 or 3 years, outcome on PD becomes equal to HD, or worse (25-28). This section mainly focuses on different means of receiving hemodialysis. 
The European Best Practice Guidelines for Hemodialysis recommends the standard hemodialysis dose should be delivered as three times per week for 4 hours each session (29). In an attempt to improve outcomes, it was postulated that a higher dialysis dose than commonly provided during conventional dialysis may increase survival among patients undergoing renal replacement therapies (30).

However, this hypothesis was refuted in two large well-designed studies in both hemodialysis and peritoneal dialysis patients:

- The HEMO study found that increasing the dialysis dose within the general restrictions of a thrice weekly regimen failed to decrease patient mortality (31).

- In the ADEMEX study, no decrease in mortality was seen with peritoneal dialysis doses greater than a weekly Kt/V of 1.7 (32)

In light of these negative studies, significant attention has turned to alternative dialysis schedules, such as, short-daily HD (SHD), nocturnal HD (NHD), and long, intermittent hemodialysis (LHD). It is suggested that more frequent dialysis may be associated an improvement in health-related quality of life (HRQoL) and with improved survival (33-34).

The first successful use of short daily, or "quotidian" hemodialysis was first reported by DePalma in 1969 (35). This approach was based upon the premise that improved patient outcomes, compared with conventional three times per week hemodialysis, would occur with a dialysis schedule that consisted of the same number of hours of dialysis per week but delivered over twice as many sessions. More specifically, it involves five to seven treatments per week, each lasting 1.5 to 2.5 hours. The rationale for short daily hemodialysis is based upon a strategy that is proposed to enhance both dialysis efficiency and hemodynamic stability. With short daily dialysis, shortening the dialysis time while increasing the frequency of dialysis allows more time to be spent dialyzing against higher uremic solute concentration gradients. This enhances the efficiency of solute removal (36). More frequent dialysis allows for less interdialytic fluid accumulation. This is likely to improve hemodynamic stability during dialysis with increased potential for normalizing the extracellular fluid volume. This form of therapy has been associated with significant improvement in serum albumin, calcium phosphate, and volume control in small scale studies. However, no mortality data is available.

A recent study, Frequent Hemodialysis Network (FHN) Daily Trial, was a multicenter, randomized trial that included 245 patients assigned to either frequent hemodialysis (six times weekly) or conventional hemodialysis. Two primary composite outcomes were determined at one year, including death or one-year change from baseline in left ventricular (LV) mass as assessed by cardiac resonance imaging, and death or one-year change in physical health as assessed by a RAND health survey. Both composite outcomes showed significant benefit to the frequent-dialysis group compared with the conventional-dialysis group (with hazard ratios of $0.61,95 \% \mathrm{CI}, 0.46-0.82$ for death or change in LV mass; and $0.70,95 \%$ CI, 0.53-0.92, for death or change in physical health) (37). This study also demonstrated benefits in pre-determined secondary outcomes to the frequent dialysis group such as a decrease in LV mass, improved blood pressure control and phosphate balance but not on cognitive performance, depression, serum albumin concentration, or use of erythropoiesis-stimulating agents.

Nocturnal hemodialysis (e.g, long nightly home hemodialysis) was introduced as a potentially more desirable alternative to conventional dialysis, since it provides superior dialysis based upon dose, duration, and frequency (38). This can be accomplished because it is performed during nightly sleep, an otherwise unproductive time (39). The late Robert 
Uldall started the first quotidian (daily) nocturnal hemodialysis program in 1994 at the Wellesley Hospital in Toronto (40). Since then, its use has been extended to more centers in Canada, the United States, Australia, and several European countries (41-44). This hemodialysis modality is performed five to seven times per week, with each treatment lasting 6 to 8 hours. Although the number of patients studied has been rather limited, but these evidence suggest signficant improvements in caloric intake and serum albumin results.

Long intermittent hemodialysis is given three times a week and a dialysis time of 6 to 8 hours. This procedure is practiced in Tassin, France, and has been associated with improvements in blood pressure control and better overall nutritional status.

Although, no data on randomized controlled trials are available on home hemodialysis, some recent well-conceived cohort studies have indicated that outcome of home (daily) HD is superior to conventional in-centre dialysis, and even equal to cadaveric transplantation, when differences in case mix are taken into account (45).

\subsection{Hemofiltration and hemodiafiltration}

Hemodiafiltration is a form of chronic renal replacement therapy used most in Europe, particularly Germany and Belgium, and very rarely used currently in the United States (46). Based upon relatively better clearance of larger "middle" molecules through solvent drag, some claim that replacement therapy with hemodiafiltration may be superior to that with hemodialysis, including improved hemodynamics.

For chronic renal replacement therapy, the two principal regimens used to provide substantial removal of larger MW uremic toxins via convection are intermittent hemofiltration (HF) and intermittent hemodiafiltration (HDF). Daily convective therapy has also been used.

- Hemofiltration - With HF, fluid is removed by the dialysis machine through increased transmembrane pressure and the replacement solution is infused intravenously at equal volume minus the desired fluid volume removal. The clearance of the method for a particular solute is dictated by the ultrafiltration volume and the sieving coefficient. As the sieving coefficient for low MW unbound solutes equals 1, the clearance for small molecules equals the ultrafiltrate volume. Although hemofiltration is effective in the removal of the larger MW solutes, it is less effective in the removal of small molecules as it is restricted by the ultrafiltration volume.

- Hemodiafiltration - HDF is a combination of hemodialysis and hemofiltration devised to overcome the low clearance of small solutes by hemofiltration by adding a diffusive component.

For chronic renal replacement therapy, the standard regimen for both HF and HDF includes three sessions per week for three to five hours, as with conventional intermittent hemodialysis. A typical conservative (or high dose) regimen for HDF includes a post dilution configuration with a blood flow of $300 \mathrm{~mL} / \mathrm{min}(500 \mathrm{~mL} / \mathrm{min}$ for high dose), a dialysate flow of $500 \mathrm{~mL} / \mathrm{min}$, a flow of a substitution volume of $60 \mathrm{~mL} / \mathrm{min}(120 \mathrm{~mL} / \mathrm{min}$ for high dose) and a high flux dialyzer of $1.4 \mathrm{~m}^{2}$ (2.2 $\mathrm{m}^{2}$ for high dose) (47).

Several small studies using daily HF/HDF have been published.

- One study that addressed the short term effects of daily HF reported that predialysis beta-2-microglobulin levels decreased by 40 percent (48).

- In one study in which 12 patients switched from HD to HF at home on a daily basis for one month, HF was associated with a lower blood pressure, higher caloric intake, and 
improved quality of life, findings consistent with previous reports on short daily HD (49-50). A trend toward a decrease in serum beta-2-microglobulin could be ascribed to the HF alone. The infusion volume used was 40 percent of total body water, which offered a standard Kt/V of approximately 2.0.

- In another study of eight patients undergoing in center daily hemodiafiltration for six months, there were lower serum levels of predialysis BUN and creatinine (which were expected by the change to a daily schedule), as well as lower levels of other solutes including beta-2-microglobulin and homocysteine (51). Additional benefits included improved phosphate control, discontinuation of all antihypertensive agents, and a 30 percent regression in left ventricular mass. Although some of these results can be attributed to the daily treatment schedule, the decrease in the pretreatment levels of beta-2-microglobulin and the improvement in phosphate control are clearly attributable to both convection and the increased treatment frequency.

\subsection{Adequacy of hemodialysis}

For greater than 50 years hemodialysis (HD) has been performed in some form or another. Outcomes for dialysis patients expressed in terms of quality of life (QOL), mortality, and hospitalization, is reportedly similar to those seen in patients with solid organ cancer. Despite improvements in long-term outcomes demonstrated with all dialysis modalities, the adjusted annual mortality of dialysis patient remains high at 19\% (52-53). There are many factors (dialysis and non-dialysis) that determines outcome. One such influential factor is "adequacy" of dialysis. Adequate dialysis was originally used to describe dialysis dosing measured by small solute removal, but is now deemed as the amount of dialysis required to keep a patient symptoms free, functional, with a life expectancy similar to that healthy individuals. Since its inception, there have been numerous approaches to quantify the delivered dialysis dose in a reproducible manner, and to link the dialysis dose with clinical outcomes.

\subsection{Importance of urea and its use as a surrogate marker of uremic toxicity}

Solute removal during hemodialysis focuses on urea. Urea is produced from the anabolism, catabolism of proteins and is the principal way by which nitrogenous substances are excreted from the body. Urea is a small water soluble molecule (molecular weight 60 daltons) that is slightly toxic. Recent studies have demonstrated that urea removal does not closely parallel that of other small water-soluble compounds, protein-bound solutes, or middle molecules. (54) Despite this information, adequacy of HD dosing is predominantly evaluated by removal of urea. During the development of the uremic syndrome, losses of kidney function are accompanied by deteriorating organ function attributable to the accumulation of uremic retention solutes or uremic toxins. (54) Uremic toxins are diverse and complex, they include inorganic compounds (phosphate water, potassium, water and trace elements), as well as organic compounds that comprises small water-soluble solutes $(<500 \mathrm{~d})$, middle molecules $(>500 \mathrm{~d})$, and protein-bound solutes. These peptides can be altered by glycosylation, oxidization or carbamylation, and they can provoke inflammation, hypertrophy, oxidative stress, coagulation, constriction, thus uremia is more than the retention and accumulation of urea or water-soluble compounds alone. (54) Mortality has repeatedly been shown to be associated with the clearance of urea. Of commonly measured protein-derived substances, only the serum concentration of $\mathrm{B}_{2}$-microglobulin correlates 
with mortality. Recently, a higher free concentration of the protein-bound solute $p$-cresol has also been reported to be associated with mortality. (55) Current dialysis and dialysis-related treatments do not remove any significant quantity of substances larger than 10 to $15 \mathrm{kd}$. Future means of removing higher molecular weight toxins or protein-bound substances may include the use of sorbents in addition to traditional diffusive and convective dialysis strategies.

\subsection{Urea kinetic modeling, URR and KT/V}

The mathematical model known as urea kinetics can be used to calculate the rate of production and removal of urea. Measurement of the dialysis dose has, for the most part, relied on estimation of clearance of the small, water-soluble, and nitrogenous waste product urea, and hence the mathematical model is referred to as urea kinetic modeling (UKM). Formal (UKM) is the most accurate method for assessment of delivered dialysis dose. It assumes that urea is distributed in a single, well-mixed pool. UKM presumes that full equilibration occurs immediately between blood and tissue compartments. However, in vivo there is a delay in redistribution and it takes 30 to 60 minutes for equilibration between blood and tissue compartments post dialysis. UKM also assumes that urea is generated at a constant rate by protein metabolism and is removed at a constant rate by residual renal function, and intermittently by dialysis. Hence, in a person with negligible renal function, the extent of urea removal provides a measure of dialysis adequacy, and the rate of production correlates with dietary protein intake. (56) Thus, it's inappropriate to follows predialysis blood urea nitrogen (BUN) or serum urea only; because low serum urea could be attributed to malnutrition (insufficient protein diet) rather than adequate dialysis urea removal. UKM has formed the basis for retrospective interpretation of the National Cooperative Dialysis Study and for prescription and control of the HEMO and the Frequent Hemodialysis Network studies. (60) Due its mathematical intricacy, UKM requires advanced computer support. UKM is the most rigorous available method for prescribing and evaluating dialysis dose and is widely used in the United States. Current methods for assessment of dialysis dose are based on the predialysis and postdialysis difference in BUN and include the urea reduction ratio (URR), the single-pool $K t / V(s p K t / V)$, the equilibrated $K t / V(e K t / V)$, and the weekly standard $K t / V(s t d-K t / V)$.

$\mathrm{Kt} / \mathrm{V}$ is a dimensionless ratio representing fractional urea clearance, where $K$ is the dialyzer urea clearance (liters per hour), $t$ is the length of HD session (hours), and $V$ is the volume of distribution of urea (liters). It is the most widely used parameter to assess dialysis dose. $\mathrm{Kt} / \mathrm{V}$ is derived from single-pool urea kinetics and is referred to as spKt/V. A value of $\mathrm{spKt} / \mathrm{V}$ of 1 indicates that the total volume of blood completely cleared of urea during a dialysis session is equivalent to the volume of distribution of urea. Solute disequilibrium occurs when dialysis time is decreased in addition to increasing dialysis and blood flow rates. Solute disequilibrium can be corrected by adjusting the Kt/V for the rebound in urea, which happens mainly in the 30-60 minutes immediately post dialysis. The resultant Kt/V is termed equilibrated $\mathrm{Kt} / \mathrm{V}$ or eKt/V. Numerous equations have been developed by Daugirdas and others to help derive the eKt/V from spKt/V.(57-59) With a conventional 4hour HD treatment, eKt/V is usually about 0.2 units lower than spKt/V. The difference is even larger with short, high-efficiency HD or hemodiafiltration, in which urea rebound is higher. Single-pool $K t / V$ or, even better, $e K t / V$ should be assessed monthly, and dialysis prescription should be adapted accordingly. In large cross-sectional studies, mortality 
increases when $s p K t / V$ falls below 1.2, and international guidelines (e.g., KDOQI) recommend a target $s p K t / V$ of 1.3 for a conventional dialysis schedule of three times per week.

Online clearance is the term used when the dialysis dose is calculated by measuring conductivity or ionic clearance across the dialysis membrane. Multiple ions can be tracked at the same time to minimize error, and the delivered $\mathrm{Kt} / \mathrm{V}$ can be predicted in real time before the treatment is over. Although sound in theory, the practical application is limited. UKM is also used to calculate the protein catabolic rate (PCR) and the protein catabolic rate normalized to body weight (nPCR), both of which are useful measures of nutrition.

Urea reduction ratio (URR) is another way of quantifying the delivered dialysis dose. However, it's over simplified since it does not take into account intradialytic urea generation and convective urea removal by ultrafiltration. Because the relative decrease in urea concentration during dialysis is the most significant determinant of $\mathrm{Kt} / \mathrm{V}$, direct measurement of URR is an accepted method for assessment of dialysis adequacy. The URR equation is as follows: $U R R=(B U N p r e-B U N p o s t) / B U N p r e$ where BUNpre is pre-dialysis urea concentration and BUNpost is post-dialysis urea concentration. By convention, the value is multiplied by 100 and expressed as a percentage. A minimum URR of $65 \%$ to $70 \%$ is recommended for adequate $\mathrm{HD}$. Kt/V and URR are mathematically linked by the following equation: $\mathrm{Kt} / \mathrm{V}=-\ln (1-\mathrm{URR})$, where $\ln$ is the natural logarithm. (60) Accordingly, $\mathrm{Kt} / \mathrm{V}$ equals 1.0 when URR equals 0.63 or $63 \%$ of whole-body urea has been removed. (60)

\subsection{Limitations of UKM}

One of the criticisms of UKM is the use of urea as the reference marker for measurement. We know that it's a very small solute. Clearance of a solute is multifactorial; it is dependent on the molecular weight, charge, volume of distribution, and protein binding. Furthermore, clearance of solutes with different molecular weights from urea or bound to proteins would be different. Thus, clearance of urea cannot be extrapolated to other substances such as "uremic toxin" because they act differently. In addition UKM does not take into account residual renal function (RRF), which has a significant impact on patient outcome. (57) Also, it has been shown that $\mathrm{V}$ calculated by anthropometric formulas systematically overestimates volume by about $15 \%$. (58) Kt/V underestimate that body water has an independent effect on outcomes, it is now recognized that smaller patients require higher $\mathrm{Kt} / \mathrm{v}$ compared to larger patients. (61) Also, Kt/V does not confer that time (t) has an independent effect on outcome. The National Cooperative Dialysis (NCDS) was the first multicenter, randomized controlled trial of hemodialysis adequacy in which UKM was used to analyse the effect of BUN and HD time. Longer time was associated with better outcomes, however the statistical relationship between treatment time and patient outcome in was considered not to be significant ( $p$ value of 0.056). (61-62) Kt/V does not account for QOL, BP and volume control, clinically stability or biochemical factors. We know from the analysis of Hurricane Katrina that patients who missed three HD sessions were associated with odds ratio for hospitalization of 2.15. $(61,63)$ Thus, Kt/V only measure the adequacy of one dialysis session, it does not incorporate missed HD sessions or shorten dialysis time.

Some of these limitations are rectifiable. One can increase HD time for intradialytic hypotension, inability to control volume, or if dialysis dosage is inadequate. HD dose can be based on body surface area (BSA), thus, smaller patients can receive more dialysis. 


\subsection{Hemodialysis dose}

Quantifying removal of toxic uremic solutes is important to assess the adequacy of HD. The delivered dialysis dose is a function of length of the session $(t)$, dialysate and blood flow rates, volume of distribution $(\mathrm{V})$ of the uremic toxin studied, and the dialyzer efficiency $\left(K_{\mathrm{o}} A\right)$. Volume of distribution is very different for urea (total body water volume), than other small-molecular-weight. The minimum frequency and dosage of dialysis is three times per week, for a minimum treatment time of 3 to 4 hours, a blood flow rate of at least 250 $\mathrm{ml} / \mathrm{min}$, and a dialysate flow rate of 500 to $800 \mathrm{ml} / \mathrm{min}$. Patients that are initiated on HD, $V$ is unknown and has to be estimated (men, $58 \%$ of body weight; women, $55 \%$ of body weight). After obtaining measured $K t / V$ the dialysis prescription can be adjusted to meet the $K t / V$ goals. For patients with severe and long-standing uremia, it's recommended to provide several sessions in achieving target dose to avoid the dialysis disequilibrium syndrome.

\subsection{Recommendations for dialysis dose adequacy}

Current recommendations in the United States are as follows (KDOQI) (64):

- A minimum $s p K t / V$ of at least 1.2 for both adult and pediatric HD patients. When URR is used, the delivered dose should be equivalent to a $K t / V$ of 1.2 , that is, an average URR of $65 \%$.

- To prevent the delivered dose of HD from falling below the recommended minimum dose, the prescribed dose of HD should be $s p K t / V$ of 1.3 , which corresponds to an average URR of $70 \%$.

- $\quad$ The delivered dose of HD should be measured at least once per month in all adult and pediatric HD patients.

\subsection{Factors affecting delivered $\mathrm{Kt} / \mathrm{V}$}

Factors that influences delivery of $\mathrm{Kt} / \mathrm{V}$ is multifactorial: hematocrit, the effective dialyzer urea clearance $K d$ depends on blood and dialysate flow rates, dialyzer $K_{0} A$, effective dialyzer surface area, anticoagulation, and recirculation. (60) Dialysis session time $(t)$ is critical for reaching the $K t / V$ goal. Prescribe treatment time (PTT) and effective treatment time (ETT) may not always correlate, EET may be significantly less secondary to patient demand, clotting of dialyser, or intermittent pump stops. $V$ does not substantially change during a single HD session but may change over time. Dialysis dose needs to be adjusted for an increase in $V$. However, if there is a loss in body mass (weight loss, amputation of limb), is associated with a decrease in $V, K t / V$ should not be reduced but rather adjusted to the higher, ideal patient $V$ or BSA.

If faced with an inadequate delivered $K t / V$, first check if that session was representative of an average session and no unusual problems may have occurred (e.g., shortened time because of patient request, needle difficulty, leaks, alarm triggering). (60) The use of commercial technologies that measure ionic dialysance can be implemented to monitor each dialysis. A frequent cause of low $K t / V$ is fistula integrity that causes a vascular access problem leading to recirculation. Blood sampling errors should be considered because delayed post-HD sampling will reduce $K t / V$. Standardized blood sampling procedures should be implemented in each center. If, despite these checks, a low $K t / V$ remains unexplained, treatment time should be increased to 4.5 or 5 hours. Prescription of a more efficient dialyzer and higher blood and dialysate flow rates should also be considered. However, increasing treatment time, rather than increasing dialysate flow, or using two 
dialysers, would be more beneficial and practical to improve adequacy. Muscle exercise before or during dialysis improves $K t / V$ by increasing blood supply to poorly perfused urea rich muscle tissue and thus facilitates urea equilibration. Delivered $K t / V$ should be checked whenever the dialysis prescription has been modified substantially. Online clearance monitoring allows assessment of $K t / V$ during each single session without blood sampling.

\subsection{Should volume (V) be included in $\mathrm{Kt} / \mathrm{V}$ to assess target clearance?}

In an attempt to address the question of optimal dialysis dose, several clinical trial have proposed that patients with small urea $V$, such as women, do worst compared to larger people. This is secondary to the notion that muscle mass closely correlate to total body water than to body weight. Thus, small urea $V$ is a good indicator for low muscle mass. The Hemodialysis Study (HEMO) was performed in which 1846 patients were randomly assigned to a standard or high dose of dialysis and a low- or high-flux dialyzer (based on clearance of beta-2-microglobulin) which revealed a beneficial effect of higher $\mathrm{Kt} / \mathrm{V}$ for women but not for men. (65) This suggests that individuals with low muscle mass may require a higher clearance in relation to $V$ and therefore raises the question of whether $V$ is the appropriate denominator for dialysis dose. (60) Native renal clearances, in contrast, are commonly related to body surface area (BSA), not to total body water. (60) It has been suggested to relate BSA to dialysis clearances. The ratio of BSA to urea $V$ is generally higher in women than in men and decreases with an increment in $V$. Prescribing dialysis dose in relation to BSA $(K \times t / \mathrm{BSA})$ would result in more dialysis for smaller patients of either gender and for women of any size. $(57,60)$ More work need to be done to validate this novel idea.

\subsection{Other dialysis factors related to outcomes}

There are many other factors that play a role in the outcome of dialysis adequacy. Such factor includes but is not restricted to middle molecule removal, hyperphosphatemia, preservation of RRF, vascular access, QOL and treatment time. In general, middle molecule removal is determined by the dialyser permeability, the presence of convection, protein binding, and dialysis duration. Given that daily dialysis results in more frequent solute level equilibration with less rebound, this technique provides higher middle molecule removal than with conventional hemodialysis. The retention of solutes of middle molecular size is proposed to play an important role in the pathogenesis of the uremic state and contribute significantly to the high mortality of dialysis patients. (60) High-flux dialyzers have the propensity to remove larger amounts of middle molecules than low-flux dialyzers due to higher membrane porosity, and this may even be further increased by the use of convective dialysis strategies, such as hemodiafiltration. Serum $\beta_{2}$-microglobulin, is a surrogate for other uremic middle molecules, is effectively removed by high-flux than by low-flux dialysis, and predialysis $\beta_{2}$-microglobulin levels were found to be related to mortality in patients treated randomly with high-flux or low-flux dialyzers. (70) Patient who has diabetes on HD, or on dialysis for longer than 3.7 years, and those with serum albumin levels below $40 \mathrm{~g} / \mathrm{l}$, may benefit most from high-flux dialysis. $(69,71)$ The European Best Practice Guidelines have recommended maximizing the removal of middle molecules in all dialysis patients. $(60,72)$

Hyperphosphatemia is a major problem in HD and is managed by phosphate removal via dialysis, use of phosphate binder medication to prevent intestinal phosphate absorption 
from dietary phosphate and dietary restriction. With the use of larger dialyzer surface area, hemodiafiltration, high-flux HD, removal of phosphate is significantly removal. Must monitor for hypophosphatemia with long frequent dialysis

End stage renal patients initiated on dialysis initially posess considerable residual renal function (RRF). However, most of these patients lose their RRF by the end of the first year on dialysis. By year three only $10 \%$ to $20 \%$ of patients retain their RRF. RRF of 2 to $3 \mathrm{ml} / \mathrm{min}$ urea clearance contributes significantly to the elimination of uremic toxins. (73) The retention of RRF results in lower serum $\beta_{2}$-microglobulin, phosphate, potassium, urea, creatinine, and uric acid levels; higher hemoglobin concentration; enhanced nutritional status; better quality of life scores; and a reduced need for dietary and fluid restrictions. (60) Left ventricular hypertrophy is associated with loss of RRF. Patient with an estimated TBW of 40 liters, a residual urea clearance of 2 to $3 \mathrm{ml} / \mathrm{min}$ is equivalent to a std-Kt/V of 0.5 to 0.75/week. Dialysate water impurities, nephrotoxic agents such as radiocontrast, nonsteroidal anti-inflammatory drugs, aminoglycosides and activation of the immune system by bioincompatible membranes, intradialytic hypotension are risk factors for the loss of RRF. Patients who retain urine output may enhance survival augment with the regulation of fluid and electrolyte balance.

\section{Frequency of dialysis}

DePalma first reported in 1969 the successful use of short daily or "quotidian" hemodialysis. (35) Short daily dialysis (SDD) was based upon the premise that patient outcomes would improved, compared with conventional three times per week hemodialysis. SDD would occur with a dialysis schedule that consisted of the same number of hours of dialysis per week but delivered over twice as many sessions. More specifically, this schedule consists of daily hemodialysis (five to seven days per week) provided for a duration of 1.5 to 3 or more hours per session. Initial attempts to popularize daily dialysis in the United States were suppressed by financial and logistical issues. This led to a decline in its use both in the home and in-center settings. However, over the last decade there has been resurgence in the use of daily dialysis, with several studies emerging from the United States and Europe showing improvements in various intermediate outcomes. Most recently, in the wake of the HEMO study, attention has turned from increasing the per-session dialytic dose, to altering variables such as treatment frequency or duration to improve outcomes (75-76) Daily dialysis has also been proposed as a rescue therapy and in the intensive care unit setting.

The mortality rate of patients undergoing maintenance hemodialysis is unacceptably high. An extremely high morbidity, relatively low quality of life (due in part to a high level of dependence and unemployment), and high cost have also been observed. Contrast this with frequent dialysis which provides a more physiological renal replacement, because it allows more gentle volume removal, reduction of hemodynamic stress and better blood pressure control. More frequent dialysis and prolonged-duration HD have the greatest effect on middle molecule clearance. (74) In addition, phosphorus removal is increased secondarily to its predominant intracellular distribution. Protein bound solutes like p-cresol are not changed, because these solutes depend on RRF. The benefits of more frequent dialysis improve BP, thus decreasing anti-hypertensive medications, decreasing intradialytic hypotension, lowering serum phosphate, raising albumin and hemoglobin with lower requirements for erythropoiesis stimulating agents. HD patients switch to nocturnal dialysis improved sleep efficiency especially in stage 3 and 4 sleep with decreased in daytime fatigue 
after 6 months. (75) Nocturnal dialysis is also associated with beneficial effects on vascular smooth muscle which restore the proliferation of the apoptosis ratio, which directly associated to serum phosphorus. However, there are no published randomized trials of nocturnal hemodialysis compared to other modalities. Thus studies comparing nocturnal hemodialysis to conventional hemodialysis should be performed to better understand the benefits with nocturnal hemodialysis.

Due to the nightly schedule with nocturnal hemodialysis, the cost of consumables is higher than conventional hemodialysis and is similar to the cost of short daily hemodialysis. However, the personnel cost of nocturnal hemodialysis is lower than that with in-center hemodialysis regimens. (76)

Depending upon the consumable/personnel cost ratio in different countries, nocturnal hemodialysis can be less or more expensive than in-center conventional hemodialysis. In addition, the cost of medications, including EPO, antihypertensive agents, and phosphate binders, is lower with nocturnal hemodialysis as well as cost of hospitalization.

\subsection{Vascular access}

Performing hemodialysis requires the ability to access and return a patient's blood at a high rate. The optimal access would allow a high rate of blood flow, with no recirculation of dialyzed blood into the pre-dialysis blood, with maximal durability, minimal complications, and minimal gap from creation to use. Currently, no hemodialysis access approaches this goal; each available access has shortcomings.

The preferred access currently is the arteriovenous fistula (AVF). The AVF is created surgically by connecting an artery to a vein, with the subsequent increased flow and pressure causing the vein to "arterialize," with thickened wall and increased size. This arterialized vein can then be accessed for hemodialysis. The advantages to the AVF are a high rate of blood flow with minimal recirculation, minimal complications because of the absence of foreign material, and an extended functional life. The primary shortcoming of the AVF is the significant time from initial placement to maturation for use, which ranges from 25 to 98 days (81). Typically AVF is not used until 3 months after placement. However, a recent study of the practice patterns at dialysis facilities in DOPPS suggests that earlier cannulation of AVFs (even prior to 4 weeks) was not associated with increased risk of access failure (81). Other issues include a significant rate of primary failure of AVFs (82), vascular steal syndrome, inability to create AVFs because of lack of suitable vessels (82-84), and development of stenoses leading to AVF thrombosis and AVF failure (82-84).

Given the significant time for their maturation, AVFs must be placed well before initiation of hemodialysis to avoid use of other accesses, such as tunneled catheters. Currently, only 15 percent of patients starting on hemodialysis use an AVF, and only 24 percent have a maturing AVF (85). One cause is late referral to nephrologists, but even with a timely referral to nephrologists, $46 \%$ of the patients did not have a permanent access placed prior to starting HD (85). Some barriers leading to this problem include patient resistance to creation of AVFs, poor access to surgeons, and decreased rate of primary patency of AVFs (85). Possible solutions include improved patient education, often through patient support groups in CKD clinics and referral to nephrologist at earlier stage of chronic kidney disease (85).

Where creation of an AVF is impossible, insertion of an arteriovenous graft (AVG) may be feasible. The advantage of an AVG is the high primary patency rate and minimal gap 
between creation and first use $(84,86)$. Because of the presence of foreign material, there is increased risk of access infection, although less than that with tunneled catheters, and there is an increased rate of stenosis, thrombosis, and graft failure compared with AVFs. One new technique in the creation of AVGs is the Hemodialysis Reliable Outflow (HeROTM) dialysis catheter, a new FDA approved device for catheter-dependent and significant vasculopathic patients. The HeRO device is an AVG that extends from the arm into the right ventricle. This may avoid problems with stenosis at the venous anastomosis leading to graft failure.

The third means of chronic hemodialysis access is the tunneled catheter. This catheter, like the standard non-tunneled dialysis catheter used for acute hemodialysis access and nontunneled catheters used for venous access, is inserted into a central vein, usually the internal jugular vein, but the risk of infection is reduced by increasing the distance between the vein and skin entry by running the catheter through a subcutaneous tunnel. This access has the advantage of being usable immediately upon insertion, but it has the highest rate of infection, particularly catheter-related bacteremia, and is associated with higher costs, morbidity, and mortality, compared with other accesses (87-88). Other complications of the tunneled catheter include intraluminal thrombosis and fibrin sheath.

\section{Management of access complications}

\subsection{Detection and treatment of stenosis and thrombosis of AVF and AVG}

Stenosis of AVF and AVG commonly develop over time, generally resulting from response to endothelial damage. This can occur at the anastamosis between native vessels or between a graft and a native vessel, with endothelial damage caused by surgical trauma, or distal to the venous anastamosis, with endothelial damage from rapid turbulent flow. If these stenoses are not recognized and corrected, increased access pressures and decreased flow can result in thrombosis of the access. Once an access has thrombosed, even if it can be salvaged, the duration of secondary patency is relatively short, with $62 \%$ one year patency average (89). Therefore, monitoring and subsequent treatment of stenosis in AVFs and AVGs is critical to prolonging the life of these hemodialysis accesses. For an excellent review of the various methods of monitoring accesses, see reference 90 . There are several ways to monitor for stenosis. Physical exam, looking for abnormalities such as change in thrill, bruit or pulse, presence of arm swelling, or prolonged bleeding after dialysis, can be quite helpful in detecting access problems (91). Another common way to detect stenosis is with dynamic venous pressure monitoring. With this technique, the pressure at the venous needle is measured with low dialysis pump rate. If the pressure is over 80 , or if there is significant increase from prior pressures, there is a high likelihood of outflow stenosis (92). Measuring static access pressures (with blood pump off) is more accurate, and can also detect arterial stenoses, but this technique requires additional equipment, and is therefore not common (93). Another monitoring method growing in use is Doppler flow measurement. If the flow decreases to less than $650 \mathrm{~mL} /$ minute, or if there has been significant interval decrease in flow, there is a high likelihood of stenosis (94). Stenoses can be detected by Doppler ultrasound, but the gold standard for detection and treatment of access stenosis is fistulogram, or the injection of contrast into the access to demonstrate visually the stenosis. When a fistulogram demonstrates stenosis, the stenosis can be repaired with angioplasty or surgical revision. While angioplasty has a shorter secondary patency than surgical revision, angioplasty is generally the first line treatment of stenosis and thrombosis of AVF and AVG, since surgical revision can be performed after angioplasty in case of recurrent stenosis or 
thrombosis (95). Treatment with anticoagulant or anti-platelet therapy, e.g. aspirin, ticlopidine or warfarin, has a modest effect on reducing stenosis and increasing patency of fistulas; however, this treatment is associated with increased risk of hemorrhage (96). Antiplatelet therapy should be a part of routine care in patient with graft but not AV fistula (97). Other pharmacological approaches for prevention of stenosis and patency of vascular access including calcium channel blocker, ACE-I and fish oil have been investigated, but further research is required to determine the role of these agents in maintaining fistula patency.

Another complication of AVF and AVG is vascular access induced ischemia and is related to significant amounts of blood flow via AV fistulas. This diversion of blood via the fistula could cause decrease of blood flow to the distal tissue and cause ischemia (known as steal syndrome). It could rarely cause exacerbation of heart failure in paints with underlying disease. Elderly patients, patients with diabetics, peripheral vascular disease or coronary artery disease are at increase risk of ischemia. Pain during hemodialysis is a characteristic symptom.

Another vascular access complication is central venous obstruction occurring in patients with previously inserted venous catheter or pacemaker placement. The rate of central venous obstruction is higher in patients who had their brachial venous accessed prior to dialysis access placement compare to patient who had internal jugular vein accessed. The most common clinical presentation is pain and swelling of the ipsilateral arm usually accompanied with the superficial collateral vein around the shoulder. Other clue for diagnosis of central venous obstruction is finger ulceration, pain and inadequate dialysis. The first option for treatment is percutaneous transluminal angioplasty and stent placement (angioplasty alone has a high rate of restenosis). The second option is surgical revision with bypass grafting and placement of HERO catheter (as discussed above).

\subsection{Catheter thrombosis and fibrin sheath formation}

One of the most common complications of hemodialysis catheters is decrease of flow or thrombosis. Catheter thrombosis prevention is generally achieved through instillation of heparin into the catheter ports after completion of dialysis; a recent study suggests that weekly instillation of recombinant tissue plasminogen activator (tPA) may prevent thrombosis more effectively (98). Catheter thrombosis can be treated effectively by instillation of tPA into the catheter lumens or with exchange of the catheter over a guidewire; however, thrombosis frequently recurs, necessitating further procedures. One cause of frequent catheter malfunction is the formation of a fibrin sheath around the tip of the catheter. This can be treated with a 3 hour infusion of low-dose tPA or with mechanical stripping, although secondary patency rates remain low (99).

\subsection{Catheter related blood stream infection (CRBSI)}

The prevalence of central venous catheters in the United States is about 20-30\% despite recommendations from major societies to increase the use of AV fistulas known as fistula first initiative. There is an increased risk of mortality with the use of catheters compared with the use of AV fistulas (100). This increased rate of mortality is likely related to infection. The rate of catheter related blood stream infection is 0.5 to 6.6 episodes per 1,000 catheter days (101). The source of this infection is bacterial seeding from biofilms that form on the inside and outside of the blood stream catheter. The rate of CRBSI is directly related 
to the species and level of virulence of the seeding bacteria. Meticulous catheter care and reeducation of personnel responsible for insertion of the catheters are the key elements in lowering the rate of catheter related infection (101). The catheter care includes but is not limited to sterile technique of catheter placement, exit -site care, sterile technique during initiation and termination of dialysis (including the use of a sterile barrier, sterile gloves, and antiseptic to clean the tubes) and the replacement of malfunctioning catheters over a guidewire (empirical administration of antibiotics does not reduce the incidence of catheter associated bacteremia) (102). Using standard antiseptic precautions the incidence of catheter related infection could drop to one episode per 1,000 catheter days which could be used to assess the quality of catheter care.

The current guidelines indicate the use of tunneled cuffed catheter for long term use (more than 3 weeks duration) in patients in need of hemodialysis based on pathophysiological considerations as well as a generally lower rate of infection of tunneled, cuffed catheters compared to nontunneled catheters (103). The location of catheters influences the risk of infection. The femoral lines carry a higher rate of infection compare with the subclavian or jugular lines. Subsequent studies, however, only confirm an increase risk of femoral catheter infection in the patients with a higher BMI $(87-88,102)$.

Although the prophylactic use of systemic antibiotics at the time of insertion of a catheter is not currently recommended, the antimicrobial lock solutions for prevention of catheter related infection and bactremia are recommended (101). The ideal lock solution has anticoagulant and antimicrobial activity, is safe, and does not induce bacterial resistance. The antimicrobial solutions most frequently used are antibiotics or chemicals, citrate $(30 \%$ concentrated since the lower concentration has little antimicrobial affect) (104). Antimicrobial lock solutions substantially reduce the risk of catheter related infection (102). The potential disadvantage of usage of antibiotics for antimicrobial lock solution is bacterial resistance and predisposition to highly resistance bacterial infection. There is also a potential adverse effect of these antibiotics including aminoglycoside-related ototoxicity. The disadvantage of usage of citrate is hypocalcemia and adverse cardiac event if the locking solution is pushed to the patient blood (105).

Application of topical antibiotics to the exit site may reduce the incidence of catheter related infection in patients on hemodialysis. The most recent CDC guideline recommends use of povidone iodine antiseptic ointment or bacitracin/gramicidin/polymyxin B at the hemodialysis catheter exit site after each dialysis session (101). A recent Cochrane review on this subject concluded that the current data support only the topical application of mupirocin alone (among antibacterial agents) for prevention of catheter related infection (106). The use of antibiotic coated catheter in hemodialysis patients has not been shown to reduce the incidence of catheter related infection $(101,107)$.

Staphylococcus species in general and S. aureus in particular are among the most common cause of bacterial related infection. Mortality rate is high among the patient infected with S. aureus $(8 \%)$. Morbidity related to $\mathrm{S}$. aureus is secondary to its high propensity to colonize prosthetic materials, heart valves, bones and joints. Nasal carriage of $S$. aureus is common among patients on dialysis, in whom it is associated with an increased risk of S. aureus infection. Successful elimination of S. aureus nasal carriage can be achieved by a short (5day) course of mupirocin applied daily to the anterior nares (108).

Treatment of CRBSI requires systemic antibiotics and frequently discontinuation of the catheter and placement of temporary catheter. There are four possible options for treatment of CRBSI. Intravenous antibiotics alone, prompt catheter removal with delayed placement of 
a new long term catheter, exchange of the infected catheter with a new one over guidewire, or use of systemic antibiotics and an antibiotic lock in the existing catheter. Antibiotic therapy for catheter-related infection is often initiated empirically. The initial choice of antibiotics will depend on the severity of the patient's clinical disease, the risk factors for infection, and the likely pathogens associated with the specific intravascular device (109). Antibiotic therapy should be administered to patients with persistent fungemia or bacteremia after catheter removal (especially if the infection is caused by S. aureus). Longterm catheters should be removed from patients with CRBSI associated with any of the following conditions: severe sepsis; suppurative thrombophlebitis; endocarditis; bloodstream infection that continues despite antimicrobial therapy to which the infecting microbes are susceptible (110). In uncomplicated CRBSI involving long-term catheters due to pathogens other than S. aureus, P. aeruginosa, fungi, because of the limited access sites in many patients who require long-term intravascular access for survival in hemodialysis patients, treatment should be attempted without catheter removal, with use of both systemic and antimicrobial lock therapy for 14 days and cultures should be repeated one week after completion of antibiotics treatment. The rate of treatment failure, however, is higher for patient treated with antibiotics alone (111). If the symptoms resolve after 2-3 days of intravenous antibiotic therapy, guidewire exchange of the catheter is associated with cure rates that are comparable to those associated with immediate removal and delayed placement of a new catheter (110). Localized Cellulites (exit site infection) should be treated with systemic antibiotics and exit site care. Tunnel track infection, however, requires catheter removal since it involves space in an area with limited vascular supply (112).

\subsection{Acute vascular access}

A large diameter venous catheter (a dual lumen venous catheter) usually placed in the internal jugular or femoral vein, is needed for acute or urgent hemodialysis in the absence of permanent vascular access. This catheter is used in patients with acute kidney injury who need urgent hemodialysis, in patients who need removal of a toxic agent by means of dialysis, or with chronic dialysis patients with a temporary inability to use a permanent access, as with catheter-related bacteremia. Using this type of access, one lumen of the venous catheter is allocated to draw blood (arterial side) and the other lumen is allocated to return the blood. Separation of arterial from venous lumen minimized the recirculation of blood during hemodialysis. Because of high risk of infection, non-tunneled femoral catheter should be removed within a week, while non-tunneled internal jugular catheters can be used for about 2 weeks. Hemodialysis catheters placed in the subclavian veins have a significant risk of subclavian stenosis, which can cause the arm on that side to be unsuitable for AVF or AVG placement, and so catheters are generally not placed in the subclavian veins. An indwelling cuffed catheter is tunneled under the skin and placed in the internal jugular vein by an interventional nephrologist, interventional radiologist or surgeon. It is used when acute renal failure is expected to require hemodialysis for more than 2 weeks because of the decreased rate of infection (1034).

\subsection{Extracorporeal therapies in the ICU setting - continuous renal replacement therapy}

Critically ill, hemodynamically unstable intensive care unit (ICU) patients are typically the most challenging to treat with conventional dialytic modalities as described above. The 
intermittent volume and solute fluxes may cause significant morbidity, which includes worsening of hypotension and arrhythmias. Multiple modalities of renal replacement therapy are currently available. These include intermittent hemodialysis (IHD), continuous renal replacement therapies (CRRTs), and hybrid therapies, such as sustained low-efficiency dialysis (SLED).

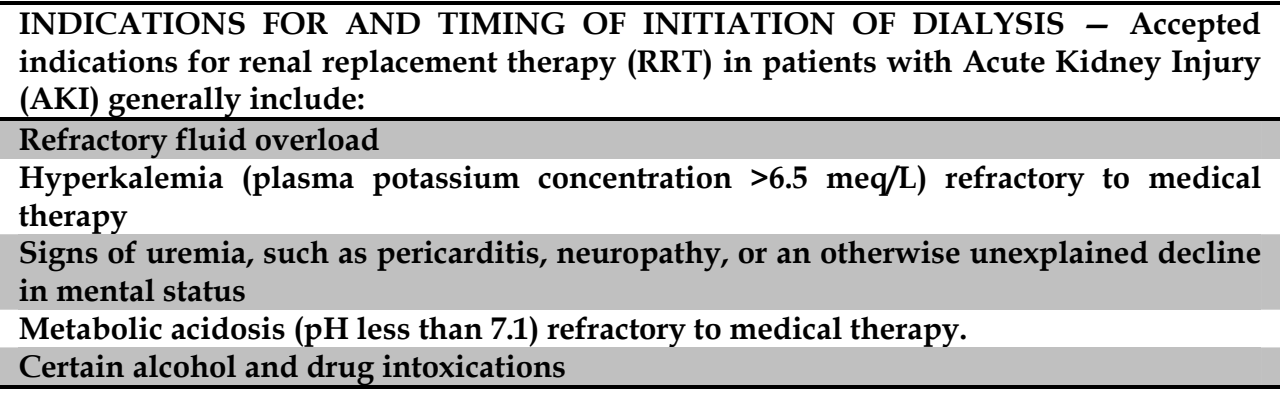

CRRTs involve either dialysis (diffusion-based solute removal) or filtration (convectionbased solute and water removal) treatments that operate in a continuous mode (114-117). The major advantage of continuous therapy is the slower rate of solute or fluid removal per unit of time. Thus, CRRT is generally better tolerated than conventional therapy, since many of the complications of intermittent hemodialysis are related to the rapid rate of solute and fluid loss. It must be emphasized, however, that the protection afforded by CRRT is relative, not absolute.

\section{Outcomes in CRRT}

Outcomes of an increased dose of CRRT have been assessed in several randomized controlled trials and two meta-analyses (78-80,116-117). Conflicting results related to survival have been reported. To address the issue of optimal dose in CRRT and IHD, the United States VA/NIH Acute Renal Failure Trial Network study (ATN), the Randomized Evaluation of Normal versus Augmented Level of RRT study (RENAL) and two metaanalyses were performed. All studies found that, compared with standard intensity dialysis, higher intensity dialysis did not result in improved survival or clinical benefits:

In the United States VA/NIH Acute Renal Failure Trial Network study (ATN), all 1124 patients were treated with IHD, CRRT, or SLED based upon hemodynamic status. Patients were randomly assigned to one of two dosing arms:

- Intensive therapy: Hemodialysis and SLED were given six times per week and a target $\mathrm{Kt} / \mathrm{V}$ of 1.2 to 1.4 per treatment, while CRRT was provided with an effluent flow rate of $35 \mathrm{~mL} / \mathrm{kg}$ per hour.

- Less intensive therapy: Hemodialysis and SLED were given three times per week, while CRRT was provided with a flow rate of $20 \mathrm{~mL} / \mathrm{kg}$ per hour.

The death rate at day 60 was the same for both groups (53.6 percent with intensive therapy and 51.5 percent with less intensive therapy). In addition, the duration of renal replacement therapy and the rate of recovery of kidney function or nonrenal organ failure were similar for both treatment arms. The group that received intensive therapy had an increased number of hypotensive episodes. Thus, more intensive renal support beyond that obtained 
with a standard thrice-weekly regimen (with a target $\mathrm{Kt} / \mathrm{V}$ of 1.2 to 1.4 per treatment) or standard CRRT (with an effluent flow rate of $20 \mathrm{~mL} / \mathrm{kg}$ per hour) does not improve clinical outcomes.

In the RENAL study (a trial in Australia and New Zealand), 1508 patients with AKI were randomly assigned to CVVHDF at an effluent flow of either 25 or $40 \mathrm{~mL} / \mathrm{kg}$ per hour (119). At 90 days, mortality was the same in each group (44.7 percent, odds ratio 1.00, 95\% CI 0.31 to 1.23). In addition, the incidence of patients who continued to receive renal replacement therapy at 90 days was similar with both dialysis doses (6.8 and 4.4 percent of higher and lower-intensity groups, odds ratio $1.59,95 \%$ CI 0.86 to 2.92 ).

Two meta-analyses, one consisting of 3841 patients and 8 trials and the other 3999 patients and 12 trials, found that more intense therapy did not improve survival compared with less intensive regimens (118-119). There was significant trial heterogeneity.

\section{References}

[1] Grassmann A, Gioberge S, Moeller S, Brown G. ESRD patients in 2004: global overview of patient numbers, treatment modalities and associated trends. Nephrol. Dial. Transplant. 2005, 20 (12): 2587-2593.

[2] United States Renal Data System. USRDS 2010 Annual Data Report: Atlas of End-Stage Renal Disease in the United States 2010; Bethesda, MD, National Institute of Health, National Institutes of Diabetes and Digestive and Kidney Diseases.

[3] Alper B, Shenava, R, Young, B, et. al. Uremia. Medscape. Batuman V. Mar 17, 2010. http:/ / emedicine.medscape.com/article/245296-overview

[4] Termorshuizen F, Dekker FW, van Manen JG et al., Relative contribution of residual renal function and different measures of adequacy to survival in hemodialysis patients: an analysis of the Netherlands Cooperative Study on the Adequacy of Dialysis (NECOSAD)-2, J Am Soc Nephrol 2004; 15:1061-70

[5] Rosansky SJ, Clark WF, Eggers P, Glassock RJ. Initiation of dialysis at higher GFRs: is the apparent rising tide of early dialysis harmful or helpful? Kidney Int. 2009 Aug;76(3):257-61.

[6] Schrier R. Manual of Nephrology: Diagnosis and Therapy. Philadelphia: Lippincott Williams \& Wilkins, 2009.

[7] Pendse, S, Singh, A, Zawada, E. Initiation of dialysis in Handbook of Dialysis, 4th ed, Daugirdas, JT, Blake, PG, Ing, TS (Eds). Lippincott Williams \& Wilkins, Philadelphia 2007.

[8] Rosansky SJ, Eggers P, Jackson K, Glassock R, Clark WF. Early Start of Hemodialysis May Be Harmful. Arch Intern Med. 2011; 171(5):396-403)

[9] NKF-KDOQI Clinical Practice Guidelines. Am J Kidney Dis 1997; 30(3 Suppl 2): S67S136.

[10] Obrador RT, Auora P, Kausz AT et al. Level of renal function at the initiation of dialysis in the US end-stage renal disease population. Kidney Int 1999; 5: 22272235.

[11] National Kidney Foundation. KDOQI Clinical practice guidelines and clinical practice recommendations for 2006 updates: hemodialysis adequacy, peritoneal dialysis adequacy and vascular access. Am J Kidney Dis 2006; 48(Suppl 1): S1-S322.

[12] Tang, SC, Ho, YW, Tang, AW, et al. Delaying initiation of dialysis till symptomatic uraemia--is it too late? Nephrol Dial Transplant 2007; 22:1926. 
[13] Cooper, BA, Branley, P, Bulfone, L, et al. A randomized, controlled trial of early versus late initiation of dialysis. N Engl J Med 2010; 363:609.

[14] Clark, W., Na, Y., Rosansky, S., et.al. Association between estimated glomerular filtration rate at initiation of dialysis and mortality. CMAJ. 2011 Jan 11;183(1):47-53.

[15] United States Renal Data System. Excerpts from the USRDS 2009 annual data report: Atlas of end-stage renal disease in the United States. Am J Kidney Dis 2010; 1(Suppl 1):S1.

[16] USRDS: The United States Renal Data System: Overall hospitalization and mortality. Am J Kidney Dis 2010; 55(Suppl 1):S1.]

[17] Van Biesen W, Vanholder R, Lameire N. The role of peritoneal dialysis as the first-line renal replacement modality. Perit Dial Int. 2000;20(4):375

[18] Goldstein A, Kliger AS, Finkelstein FO. Recovery of renal function and the discontinuation of dialysis in patients treated with continuous peritoneal dialysis.Perit Dial Int. 2003;23(2):151

[19] Teitelbaum I, Burkart J. Peritoneal dialysis. Am J Kidney Dis. 2003;42(5):1082

[20] Wauters JP, Uehlinger D. Non-medical factors influencing peritoneal dialysis utilization: the Swiss experience. Nephrol Dial Transplant. 2004;19(6):1363

[21] Mendelssohn DC, Langlois N, Blake PG. Peritoneal dialysis in Ontario: a natural experiment in physician reimbursement methodology. Perit Dial Int. 2004;24(6):531

[22] Tonelli M, Hemmelgarn B, Culleton B, Klarenbach S, Gill JS, Wiebe N, Manns B, Alberta Kidney Disease Network. Mortality of Canadians treated by peritoneal dialysis in remote locations. Kidney Int. 2007;72(8):1023

[23] Mehrotra R, Khawar O, Duong U, Fried L, Norris K, Nissenson A, Kalantar-Zadeh K. Ownership patterns of dialysis units and peritoneal dialysis in the United States: utilization and outcomes. Am J Kidney Dis. 2009;54(2):289.

[24] Korevaar JC, Feith GW, Dekker FW, et al. Effect of starting with hemodialysis compared with peritoneal dialysis in patients new on dialysis treatment: a randomized controlled trial. Kidney Int 2003;64:2222-2228.

[25] Ganesh SK, Hulbert-Shearon T, Port FK, et al. Mortality differences by dialysis modality among incident ESRD patients with and without coronary artery disease. J Am Soc Nephrol 2003;14:415-424

[26] Stack AG, Molony DA, Rahman NS, et al. Impact of dialysis modality on survival of new ESRD patients with congestive heart failure in the United States. Kidney Int 2003;64:1071-1079

[27] Vonesh EF, Snyder JJ, Foley RN, et al. The differential impact of risk factors on mortality in hemodialysis and peritoneal dialysis. Kidney Int 2004;66:2389-2401

[28] Jaar BG, Coresh J, Plantinga LC, et al. Comparing the risk for death with peritoneal dialysis and hemodialysis in a national cohort of patients with chronic kidney disease. Ann Intern Med 2005;143:174-183.

[29] Tattersall J, Martin-Malo A, Pedrini L, Basci A, Canaud B, Fouque D, Haage P, Konner K, Kooman J, Pizzarelli F, Tordoir J, Vennegoor M, Wanner C, ter Wee P, Vanholder R: EBPG guideline on dialysis strategies. Nephrol Dial Transplant 22[Suppl 2]: ii5-ii21, 2007.

[30] Lowrie, E, Laird, NM. National Cooperative Dialysis Study. Kidney Int Suppl 1983; 23:19. 
[31] Eknoyan G, Beck GJ, Cheung AK, Daugirdas JT, Greene T, Kusek JW, Allon M, Bailey J, Delmez JA, Depner TA, Dwyer JT, Levey AS, Levin NW, Milford E, Ornt DB, Rocco MV, Schulman G, Schwab SJ, Teehan BP, Toto R, Hemodialysis (HEMO) Study Group. Effect of dialysis dose and membrane flux in maintenance hemodialysis. N Engl J Med. 2002;347(25):2010.

[32] Paniagua R, Amato D, Vonesh E, Correa-Rotter R, Ramos A, Moran J, Mujais S, Mexican Nephrology Collaborative Study Group. Effects of increased peritoneal clearances on mortality rates in peritoneal dialysis: ADEMEX, a prospective, randomized, controlled trial. J Am Soc Nephrol. 2002;13(5):1307

[33] Tattersall J, Martin-Malo A, Pedrini L, Basci A, Canaud B, Fouque D, Haage P, Konner K, Kooman J, Pizzarelli F, Tordoir J, Vennegoor M, Wanner C, ter Wee P, Vanholder R: EBPG guideline on dialysis strategies. Nephrol Dial Transplant 22[Suppl 2]: ii5-ii21, 2007

[34] Kjellstrand CM, Buoncristiani U, Ting G, Traeger J, Piccoli GB, Sibai-Galland R, Young BA, Blagg CR: Short daily haemodialysis: Survival in 415 patients treated for 1006 patient-years. Nephrol Dial Transplant 23: 3283-3289, 2008.

[35] DePalma, JR, Pecker, EA, Maxwell, MH. A new automatic coil dialyser system for 'daily' dialysis. Proc EDTA 1969; 6:26....DePalma, JR, Pecker, EA, Maxwell, MH. A new automatic coil dialyser system for 'daily' dialysis. Semin Dial 1999; 12:410.

[36] Henderson LW, Leypoldt JK, Lysaght MJ, Cheung AK. Death on dialysis and the time/flux trade-off. Blood Purif. 1997;15(1):1.

[37] FHN Trial Group, Chertow GM, Levin NW, Beck GJ, Depner TA, Eggers PW, Gassman JJ, Gorodetskaya I, Greene T, James S, Larive B, Lindsay RM, Mehta RL, Miller B, Ornt DB, Rajagopalan S, Rastogi A, Rocco MV, Schiller B, Sergeyeva O, Schulman G, Ting GO, Unruh ML, Star RA, Kliger AS. In-center hemodialysis six times per week versus three times per week. N Engl J Med. 2010;363(24):2287.

[38] Kalirao P and Kaplan JM, Nocturnal Hemodialysis, Clin Exp Nephrol 2009; 13:257-62

[39] Pierratos A, Ouwendyk M, Francoeur R, Vas S, Raj DS, Ecclestone AM, Langos V, Uldall R. Nocturnal hemodialysis: three-year experience. J Am Soc Nephrol. 1998;9(5):859.

[40] Udall, PR, Francoeur, R, Ouwendyk, M. Simplified nocturnal home hemodialysis (SNHHD). A new approach to renal replacement therapy. J Am Soc Nephrol 1994; $5: 428$

[41] Lindsay RM, Daily/Nocturnal Dialysis Study Group. The London, Ontario, Daily/Nocturnal Hemodialysis Study. Semin Dial. 2004;17(2):85

[42] Lockridge RS Jr, Spencer M, Craft V, Pipkin M, Campbell D, McPhatter L, Albert J, Anderson H, Jennings F, Barger T. Nocturnal home hemodialysis in North America. Adv Ren Replace Ther. 2001;8(4):250.

[43] Agar JW, Somerville CA, Dwyer KM, Simmonds RE, Boddington JM, Waldron CM. Nocturnal hemodialysis in australia. Hemodial Int. 2003;7(4):278.

[44] Kooistra MP. Frequent prolonged home haemodialysis: three old concepts, one modern solution. Nephrol Dial Transplant. 2003;18(1):16.

[45] Kjellstrand CM, Buoncristiani U, Ting G, et al. Short daily haemodialysis: survival in 415 patients treated for 1006 patient-years. Nephrol Dial Transplant 2008;23:32833289 . 
[46] ERA-EDTA Registry: Annual Academic Medical Center. Amsterdam, The Netherlands, 2003.

[47] Wizemann V, Külz M, Techert F, Nederlof B. Efficacy of haemodiafiltration. Nephrol Dial Transplant. 2001;16 Suppl 4:27.

[48] Canaud B, Assounga A, Kerr P, Aznar R, Mion C. Failure of a daily haemofiltration programme using a highly permeable membrane to return beta 2-microglobulin concentrations to normal in haemodialysis patients. Nephrol Dial Transplant. 1992;7(9):924.

[49] Jaber BL, Zimmerman DL, Teehan GS, Swedko P, Burns K, Meyer KB, Leypoldt JK. Daily hemofiltration for end-stage renal disease: a feasibility and efficacy trial. Blood Purif. 2004;22(6):481.

[50] Zimmerman, DL, Swedko, P, Posen, G, Burns, K. Daily hemofiltration with a simplified method of delivery. J Am Soc Nephrol 2002; 13:61A.

[51] Maduell F, Navarro V, Torregrosa E, Rius A, Dicenta F, Cruz MC, Ferrero JA. Change from three times a week on-line hemodiafiltration to short daily on-line hemodiafiltration. Kidney Int. 2003;64(1):305.

[52] US Renal Data System: USRDS 2008 Annual Data Report: Atlas of Chronic Kidney Disease and End Stage Renal Disease in the United States, Bethesda, NIH, National Institute of Diabetes and Digestive and Kidney Disease, 2008

[53] US Renal Data System: USRDS 2008 Annual Data Report: Atlas of Chronic Kidney Disease and End Stage Renal Disease in the United States, Bethesda, NIH, National Institute of Diabetes and Digestive and Kidney Disease, 2009

[54] Vanholder R, Van Laecke S, Glorieux G: What is new in uremic toxicity? Pediatr Nephrol 2008; 23:1211-1221.

[55] Vanholder R, De Smet R, Glorieux G, et al: Review on uremic toxins: Classification, concentration, and interindividual variability. Kidney Int 2003; 63:1934-1943.

[56] Ankit N. Mehta, MD; Andrew Z. Fenves, MD: Hemodialysis Adequacy: A Review; January 2010 Dialysis \& Transplantation

[57] Daugirdas JT. Simplifi ed equations for monitoring Kt/V, PCRn, eKt/V, and ePCRn. Adv Renal Replace Ther. 1995; 2:295-304.

[58] Tattersall JE, DeTakats D, Chamney P, Greenwood RN, Farrington K. The posthemodialysis rebound: predicting and quantifying its effect on Kt/V. Kidney Int. 1996; 50: 2094-2102.

[59] Leypoldt JK, Jaber BL, Zimmerman DL. Predicting treatment dose for novel therapies using urea standard Kt/V. Semin Dial. 2004; 17:142-145.

[60] Feehally, J, Floege, J, Johnson, R. The Comprehensive Clinical Nephrology. Chapter 90; Hemodialysis: Outcomes and Adequacy. Copyright (C) 2010 Elsevier

[61] Agarwal, R, Mehrotra, R, Townsend RR, Goldfarb, S. NephSap, Vo19, No. 6, November 2010;pp 366-371

[62] Powell JR, Oluwaseum O, Woo YM, Padmanabhan N, Narasingham E, Latta C, Tortolana J, Jardine AG, Geddes CC. Ten year experience of in-center thrice weekly long overnight hemodialysis. Clin J Am Soc Nephrol 4:1097-1101, 2009

[63] Anderson AH, Cohen AJ, Kutner NG, Kopp JB, Kimmel PL, Mutner P; Missed dialysis sessions and hospitalization in hemodialysis patients after Hurricane Katrina. Kidney Int 75:1202-1208, 2009 
[64] National Kidney Foundation : KDOQI Clinical Practice Guidelines and Clinical Practice Recommendations for 2006 Updates: Hemodialysis Adequacy, Peritoneal Dialysis Adequacy and Vascular Access. Am J Kidney Dis 2006; 48(Suppl 1):S1S322

[65] Eknoyan G, Beck GJ, Cheung AK, Daugirdas JT, Greene T, Kusek JW, Allon M, Bailey J, Delmez JA, Depner TA, Dwyer JT, Levey AS, Levin NW, Milford E, Ornt DB, Rocco MV, Schulman G, Schwab SJ, Teehan BP, Toto R, Effect of dialysis dose and membrane flux in maintenance hemodialysis. N Engl J Med. 2002; 347(25):2010. Hemodialysis (HEMO) Study Group

[66] DePalma, JR, Pecker, EA, Maxwell, MH. A new automatic coil dialyser system for 'daily' dialysis. Proc EDTA 1969; 6:26.

[67] DePalma, JR, Pecker, EA, Maxwell, MH. A new automatic coil dialyser system for 'daily' dialysis. Semin Dial 1999; 12:410.

[68] Uldall, PR, Francoeur, R, Ouwendyk, M. Simplified nocturnal home hemodialysis (SNHHD). A new approach to renal replacement therapy. J Am Soc Nephrol 1994; 5:428.

[69] Pierratos A, Ouwendyk M, Francoeur R, et al. Nocturnal hemodialysis: three-year experience. J Am Soc Nephrol 1998; 9:859.

[70] Cheung AK, Rocco MV, Yan G, et al: Serum $\beta 2$-microglobulin levels predict mortality in dialysis patients: Results of the HEMO study. J Am Soc Nephrol 2006; 17:546555.

[71] Locatelli F, Martin-Malo A, Hannedouche T, et al: Effect of membrane permeability on survival of hemodialysis patients. J Am Soc Nephrol 2009; 20:645-654.

[72] European Best Practice Guidelines Expert Group on Hemodialysis, European Renal Association. Nephrol Dial Transplant 2002; 17(Suppl 7):16-31.

[73] Bargman JM, Golper TA: The importance of residual renal function for patients on dialysis. Nephrol Dial Transplant 2005; 20:671-673.

[74] Kliger AS, More Intensive hemodialysis. Clin J Am Soc Nephrol 4[suppll 1] S121-S124, 2009

[75] Beecroft JM, Hoffstein V, Pierratos A, Chan Ct, McFarlane P, Hanly PJ, Nocturnal heamodialysis increases pharyngeal size in patients with sleep apnea and end stage renal disease. Nephrol Dialy Transplant 23: 673-679, 2008

[76] McFarlane PA Reducing hemodialysis costs: conventional and quotidian home hemodialysis in Canada. Semin Dial. 2004: 17(2):118.

[77] Manns M, Sigler MH, Teehan BP. Continuous renal replacement therapies: an update. Am J Kidney Dis. 1998;32(2):185.

[78] Bouman CS, Oudemans-Van Straaten HM, Tijssen JG, Zandstra DF, Kesecioglu J. Effects of early high-volume continuous venovenous hemofiltration on survival and recovery of renal function in intensive care patients with acute renal failure: a prospective, randomized trial. Crit Care Med. 2002;30(10):2205.

[79] Ronco C, Bellomo R, Homel P, Brendolan A, Dan M, Piccinni P, La Greca G. Effects of different doses in continuous veno-venous haemofiltration on outcomes of acute renal failure: a prospective randomised trial. Lancet. 2000;356(9223):26

[80] Saudan P, Niederberger M, De Seigneux S, Romand J, Pugin J, Perneger T, Martin PY. Adding a dialysis dose to continuous hemofiltration increases survival in patients with acute renal failure. Kidney Int. 2006;70(7):1312. 
[81] Creation, cannulation and survival of arteriovenous fistulae: Data from the Dialysis Outcomes and Practice Patterns Study. Kidney International; Jan2003, Vol. 63 Issue 1, p323-330, 8p

[82] Schild AF: Maintaining vascular access: the management of hemodialysis arteriovenous grafts. Vasc Access. 2010 Apr-Jun;11(2):92-9.

[83] Robin M et al. Hemodialysis Arteriovenous Fistula Maturity: US Evaluation Radiology 2002, vol 221:1, 59-64

[84] Biuckians A, Scott EC, Meier GH, et al: The natural history of autologous fistulas as first-time dialysis access in the KDOQI era. J Vasc Surg 2008; 47:415-421.

[85] Ronald L Pisoni, Eric W Young, Dawn M Dykstra, Roger N Greenwood, Erwin Hecking, Brenda Gillespie, Robert A Wolfe, David A Goodkin and Philip J HeldVascular access use in Europe and the United States: Results from the DOPPS, Kidney International (2002) 61, 305-316

[86] Lazarides MK, Georgiadis GS, Papasideris CP, et al: Transposed brachial-basilic arteriovenous fistulas versus prosthetic upper limb grafts: A meta-analysis. Eur J Vasc Endovasc Surg 2008; 36:597-601.

[87] Parienti, J. J. et al. Femoral vs jugular venous catheterization and risk of nosocomial events in adults requiring acute renal replacement therapy: a randomized controlled trial. JAMA 299, 2413-2422 (2008).

[88] Hamilton, H. C. \& Foxcroft, D. R. Central venous access sites for the prevention of venous thrombosis, stenosis and infection in patients requiring long-term intravenous therapy. Cochrane Database of Systematic Reviews, Issue 3. Art. No.: CD004084. doi:10.1002/14651858.CD004084.pub2 (2007).

[89] Kakkos SK, Haddad GK, Haddad JA et al., Secondary patency of thrombosed prosthethc vascular access grafts with aggressive surveillance, monitoring, and endovascular management, Eur J Endovasc Surg 2008; 36:356-65

[90] Tessitore N, Bedogna V, Melilli E et al., In search of an optimal bedside screening program for arteriovenous fistula stenosis, Clin J Am Soc Nephrol 2011; 6:819-26

[91] Beathard GA, An algorithm for the physical examination of early fistula failure, Semin Dial 2005; 18:331-335

[92] Besarab A, Asif A, Roy-Chaudury P et al., The native arteriovenous fistula in 2007. Surveillance and monitoring. J Nephrol 2007; 20:656-667

[93] Besarab A, Sullivan KL, Ross R et al., The utility of intra-access monitoring in detecting and correcting venous outlet stenoses prior to thrombosis, Kidney Int 1995; 13641373

[94] Tessitore N, Bedogna V, Gammaro L et al., Diagnostic accuracy of ultrasound dilution access blood flow measurement in detecting stenosis and predicting thrombosis in native forearm arteriovenous fistulae for hemodialysis, Am J Kidney Dis 2003; 42:331-341

[95] Napoli M, Prudenzano R, Russo F et al., Juxta-anastomotic stenosis of native arteriovenous fistulas: surgical treatment versus percutaneous transluminal angioplasty, J Vasc Access 2010; 11:346-351

[96] Dixon BS, Beck GJ, Vazquez MA, et al: Effect of dipyridamole plus aspirin on hemodialysis graft patency. N Engl J Med 2009; 360:2191-2201. 
[97] Dember LM, Besk GJ, Allon M, et al: Effect of clopidogrel on early failure of arteriovenous fistulas for hemodialysis: A randomized controlled trial. JAMA 2008; 299:2205-2207

[98] Hemmelgarn BR, Moist LM, Lok CE et al., Prevention of dialysis catheter malfunction with recombinant tissue plasminogen activator, N Engl J Med 2011; 364:303-312

[99] Kamper L, Piroth, W, and Haage P, Endovascular treatment of dysfunctional hemodialysis catheters, J Vasc Access 2010; 11:263-268

[100] Allon M, Daugirdas J, Depner TA, et al: Effect of change in vascular access on patient mortality in hemodialysis patients. Am J Kidney Dis 2006; 47:469-477

[101] 2011 CDC Guidelines for the Prevention of Intravascular Catheter-Related Infections

[102] Rabindranath, K. S. et al. Systematic review of antimicrobials for the prevention of haemodialysis catheter-related infections. Nephrol. Dial. Transplant. 24, 3763-3774 (2009).

[103] Vanholder, R. et al. Diagnosis, prevention and treatment of haemodialysis catheterrelated bloodstream infections (CRBSI): a position statement of the European Renal Best Practice (ERBP). NDTPlus 3, 234-246 (2010).

[104] Dogra GK, Herson H, Hutchison B, et al. Prevention of tunneled hemodialysis catheter-related infections using catheter-restricted filling with gentamicin and citrate: a randomized controlled study. J Am Soc Nephrol 2002; 13:2133-9

[105] Punt, C. D. \& Boer, W. E. Cardiac arrest following injection of concentrated trisodium citrate. Clin. Nephrol. 69, 317-318 (2008)

[106] McCann, M. \& Moore, Z. E. H. Interventions for preventing infectious complications in haemodialysis patients with central venous catheters. Cochrane Database of Systematic Reviews, Issue 1. Art. No.: CD006894. doi:10.1002/14651858.CD006894.pub2 (2010)

[107] Chatzinikolaou, I. et al. Antibiotic-coated hemodialysis catheters for the prevention of vascular catheter-related infections: a prospective, randomized study. Am. J. Med. 115, 352-357 (2003).

[108] von Eiff, C. et al. Nasal carriage as source of Stapylococcus aureus bacteremia. Study Group. N. Engl. J. Med. 344, 11-16 (2001)

[109] Wilcox MH, Tack KJ, Bouza E, et al. Complicated skin and skin structure infections and catheter-related bloodstream infections: noninferiority of linezolid in a phase 3 study. Clin Infect Dis 2009; 48: 203-12.

[110] Clinical practice guidelines for the diagnosis and management of intravascular catheter-related infection: 2009 Update by the Infectious Diseases Society of America

[111] Mokrzycki MH, Zhang M, Cohen H, Golestaneh L, Laut JM, Rosenberg SO. Tunnelled haemodialysis catheter bacteraemia: risk factors for bacteraemia recurrence, infectious complications and mortality. Nephrol Dial Transplant 2006; 21:1024-31

[112] NKF-K/DOQI Clinical Practice Guidelines for Vascular Access: update 2000. Am J Kidney Dis 2001; 37:S137-S181

[113] McCarthy JT, Moran J, Posen G, Leypoldt JK, Hull AR, Jaber BL, Correa-Rotter R. A time for rediscovery: chronic hemofiltration for end-stage renal disease. Semin Dial. 2003;16(3):199. 
[114] Honore PM, Jamez J, Wauthier M, Lee PA, Dugernier T, Pirenne B, Hanique G, Matson JR. Prospective evaluation of short-term, high-volume isovolemic hemofiltration on the hemodynamic course and outcome in patients with intractable circulatory failure resulting from septic shock. Crit Care Med. 2000;28(11):3581.

[115] Palevsky PM. Dialysis modality and dosing strategy in acute renal failure. Semin Dial. 2006;19(2):165.

[116] Tolwani AJ, Campbell RC, Stofan BS, Lai KR, Oster RA, Wille KM. Standard versus high-dose CVVHDF for ICU-related acute renal failure. J Am Soc Nephrol. 2008;19(6):1233.

[117] Jun M, Heerspink HJ, Ninomiya T, Gallagher M, Bellomo R, Myburgh J, Finfer S, Palevsky PM, Kellum JA, Perkovic V, Cass A. Intensities of renal replacement therapy in acute kidney injury: a systematic review and meta-analysis. Clin J Am Soc Nephrol. 2010;5(6):956.

[118] Van Wert R, Friedrich JO, Scales DC, Wald R, Adhikari NK, University of Toronto Acute Kidney Injury Research Group. High-dose renal replacement therapy for acute kidney injury: Systematic review and meta-analysis. Crit Care Med. 2010;38(5):1360.

[119] RENAL Replacement Therapy Study Investigators, Bellomo R, Cass A, Cole L, Finfer S, Gallagher M, Lo S, McArthur C, McGuinness S, Myburgh J, Norton R, Scheinkestel $\mathrm{C}$, Su S. Intensity of continuous renal-replacement therapy in critically ill patients. N Engl J Med. 2009;361(17):1627.

[120] Vesconi S, Cruz DN, Fumagalli R, Kindgen-Milles D, Monti G, Marinho A, Mariano F, Formica M, Marchesi M, René R, Livigni S, Ronco C, DOse REsponse Multicentre International collaborative Initiative (DO-RE-MI Study Group). Delivered dose of renal replacement therapy and mortality in critically ill patients with acute kidney injury. Crit Care. 2009;13(2):R57. 


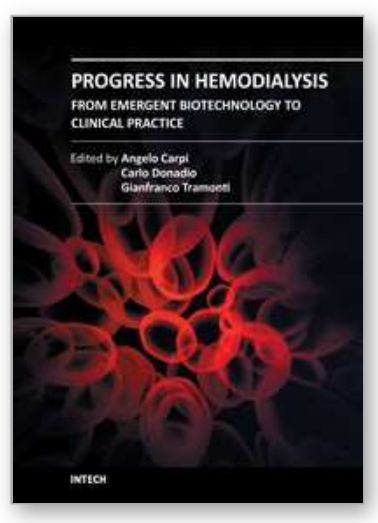

\section{Progress in Hemodialysis - From Emergent Biotechnology to Clinical Practice}

Edited by Prof. Angelo Carpi

ISBN 978-953-307-377-4

Hard cover, 444 pages

Publisher InTech

Published online 07, November, 2011

Published in print edition November, 2011

Hemodialysis (HD) represents the first successful long-term substitutive therapy with an artificial organ for severe failure of a vital organ. Because HD was started many decades ago, a book on HD may not appear to be up-to-date. Indeed, HD covers many basic and clinical aspects and this book reflects the rapid expansion of new and controversial aspects either in the biotechnological or in the clinical field. This book revises new technologies and therapeutic options to improve dialysis treatment of uremic patients. This book consists of three parts: modeling, methods and technique, prognosis and complications.

\section{How to reference}

In order to correctly reference this scholarly work, feel free to copy and paste the following:

Parin Makadia, Payam Benson, Filberto Kelly and Joshua Kaplan (2011). Hemodialysis Principles and Controversies, Progress in Hemodialysis - From Emergent Biotechnology to Clinical Practice, Prof. Angelo Carpi (Ed.), ISBN: 978-953-307-377-4, InTech, Available from: http://www.intechopen.com/books/progress-inhemodialysis-from-emergent-biotechnology-to-clinical-practice/hemodialysis-principles-and-controversies

\section{INTECH}

open science | open minds

\section{InTech Europe}

University Campus STeP Ri

Slavka Krautzeka 83/A

51000 Rijeka, Croatia

Phone: +385 (51) 770447

Fax: +385 (51) 686166

www.intechopen.com

\section{InTech China}

Unit 405, Office Block, Hotel Equatorial Shanghai

No.65, Yan An Road (West), Shanghai, 200040, China

中国上海市延安西路65号上海国际贵都大饭店办公楼405单元

Phone: +86-21-62489820

Fax: $+86-21-62489821$ 
(C) 2011 The Author(s). Licensee IntechOpen. This is an open access article distributed under the terms of the Creative Commons Attribution 3.0 License, which permits unrestricted use, distribution, and reproduction in any medium, provided the original work is properly cited. 